\title{
rs4889 polymorphism in KISS1 gene, its effect on polycystic ovary syndrome development and anthropometric and hormonal parameters in Saudi women
}

Fadwa S. Albalawi ${ }^{1}$, Maha H. Daghestani ${ }^{1 *}$, Mazin H. Daghestani ${ }^{2}$, Abdelmoneim Eldali ${ }^{3}$ and Arjumand S. Warsy ${ }^{4}$

\begin{abstract}
Background: Kisspeptin is involved in female reproduction. This study was designed to i- estimate kisspeptin levels in women with polycystic ovary syndrome (PCOS), in comparison with controls, ii- study the correlations between kisspeptin and PCOS-related reproductive hormones, and iii- investigate the relation between KISS1 gene polymorphisms and hormone levels in women suffering from PCOS.

Methods: The investigation was a clinically designed study on 28 women with PCOS, and 30 normal, healthy women with no signs of PCOS as controls. Blood samples were collected between day 3 and day 6 of the menstrual cycle in both groups at 8:00 a.m., and circulating levels of LH, FSH and kisspeptin were estimated. DNA was extracted from whole blood and all coding exons of KISS1 gene were sequenced.

Results: Women with PCOS had higher LH levels and BMI compared to controls. Plasma kisspeptin levels were positively correlated with LH levels. There was no statistically significant difference between the groups in terms of kisspeptin and FSH levels. The SNP rs4889 C/G, a non-synonymous SNP, was investigated in the PCOS group. The frequency of GG genotype was significantly higher in the PCOS compared to the controls. These patients were more obese, had higher kisspeptin and FSH levels.

Conclusion: The results of the study show that the genetic variation of KISSI gene may be a factor contributing to PCOS development. The association between the gene and the gene variation and PCOS need further validation in large-scaled and functional studies.
\end{abstract}

Keywords: KISS1 gene, Kisspeptin, LH, FSH, GPR54, PCOS

\section{Background}

Kisspeptin is a 54-amino-acid peptide encoded by the KISS1 gene, and is also known as metastin [1, 2], which was first isolated from the human placenta in 2001 [3]. Kisspeptin action is exerted by a trans-membrane G-protein coupled receptor, named GPR54, AXOR12, or HoT7T175 [4]. Loss of KISS1 gene function is reported to be associated with hypogonadotropic hypogonadism in humans and animal models $[5,6]$. Binding of kisspeptin to its receptor (GPR54) in the GnRH neurons in the hypothalamus, results

\footnotetext{
* Correspondence: mdaghestani@ksu.edu.sa

${ }^{1}$ Department of Zoology, Center for Scientific and Medical Female Colleges, King Saud University, P.O. Box 22455, Riyadh 11495, Saudi Arabia Full list of author information is available at the end of the article
}

in the stimulation of gonadotropin release, which in turn binds to the GnRH receptors in the pituitary and influences the release of LH and FHS [7]. These hormones act on the gonads and influence estrogen, testosterone and progesterone release. Hence, kisspeptin has been shown to regulate the secretion of luteinizing hormone (LH) during the promotion of ovulation [8] by stimulating gonadotropin releasing hormone $(\mathrm{GnRH})$ from the hypothalamus $[9,10]$.

The polycystic ovary syndrome (PCOS) is a common heterogeneous disorder affecting women, with a prevalence of $6-12 \%$ in women of reproductive age [11]. It is of complex pathogenesis, characterized by hypothalamic-pituitary disturbances in gonadotropin secretion, specifically increased 
LH levels [12, 13], chronic anovulation, and polycystic ovaries (PCO) on ultrasound. In addition, patients frequently suffer from hyperinsulinemia, insulin resistance [14], type 2 diabetes mellitus (DM), cardio-vascular disease and infertility $[15,16]$. Given the complex relationship between kisspeptin and hypothalamic-pituitary gonadal axis, the present study aimed to investigate the relation between KISS1, BMI, FSH and LH and the influence of KISS1 gene polymorphisms on these parameters in normal women and those suffering from PCOS.

\section{Methods}

\section{Subjects}

The samples were collected from Al-Hira Hospital in Makkah Al Mukarama, from 58 Saudi women volunteers aged 19-36 after obtaining Ethical Committee approval, from the Institutional Review Board. Each participant gave a written informed consent prior to enrolment in the study. A total of 58 Saudi women volunteers aged 19-36 years were recruited. Cases were 28 Saudi women attending the outpatient clinics and fulfilling the following criteria:

- Oligomenorrhoea (cycle duration between 35 days to

3 months).

$\circ$ Transvaginal ultrasound image of enlarged ovaries

with $>10$ cysts in the largest plane; each measuring

$<\mathrm{I} 0 \mathrm{~mm}$ in diameter scattered around an echodense

thickened stroma [17]

- None had received any drugs known to interfere with hormonal concentrations for at least 3 months before the study.

Controls were 30 Saudi women volunteers representing cross section of Saudi society. All subjects were healthy, had spontaneous onset of puberty and sexual development, with regular menstrual cycle, and no history of gastrointestinal or endocrine disorders.

\section{Anthropometric measurements}

Anthropometric measurements included body weight, height and body mass index (BMI), (weight in $\mathrm{Kg}$ divided by height in $\mathrm{m}^{2}$ ).

\section{Laboratory methods}

Blood samples were collected between day 3 and day 6 of a menstrual cycle in the PCOS and control groups, all blood samples were obtained at 8:00 a.m. (This ensured obtaining the true level of the reproductive hormones, as these hormones show variations with the days of the menstrual cycle). Five milliliter of blood was drawn by venipuncture in red top tube for kisspeptin, FSH and LH estimations.
In addition, $5 \mathrm{~mL}$ of blood was collected in EDTA-coated tubes for DNA extraction. All blood samples for each subject were immediately centrifuged, and plasma, serum and buffy coat were stored at $-80{ }^{\circ} \mathrm{C}$ until analysis. Kisspeptin levels were measured with an enzyme-linked immunoassay kit (ELISA kit, Phoenix Pharmaceuticals Inc., Belmond, CA), after extraction with Phoenix Peptide sep-columns (RK-Sepcol-2). FSH and LH levels were measured with an enzyme-linked immunoassay kit (ELISA kit, Human, cat.No.65205.GER).

\section{Genotyping of KISS1 gene polymorphism}

Genomic DNA was extracted from peripheral blood leucocytes using commercially available Puregene Blood Kit (QIAGEN, cat. No. 158389, USA). Polymorphism was determined by sequencing following polymerase chain reaction (PCR), using forward and reverse primers. The primers were designed using PRIMER 3 program and the sequence of each primer was as follows:

F: 5' - ACCTGCCGAACTACAACTGG-3'; R: 5'-TGAA GGAACAGGCGGTTAGT -3'.

The PCR conditions consisted of initial denaturation step at $95{ }^{\circ} \mathrm{C}$ for $15 \mathrm{~min}$, followed by 34 cycles of denaturation at $95{ }^{\circ} \mathrm{C}$ for $1 \mathrm{~min}$, annealing at $60{ }^{\circ} \mathrm{C}$ for $1 \mathrm{~min}$, and extension at $72{ }^{\circ} \mathrm{C}$ for $1 \mathrm{~min}$, with final extension of $10 \mathrm{~min}$ at $72{ }^{\circ} \mathrm{C}$. A PCR product of $353 \mathrm{bp}$ was obtained. Nucleotide sequencing was carried out using the ABI Big Dye Terminator protocol on ABI 3100 Avant Genetic Analyzer.

\section{Statistical analyses}

The descriptive characteristics of the group variables were expressed as mean \pm SEM. The comparisons between PCOS patients and their matched controls were carried out using the independent $\mathrm{t}$-test and ANOVA test with respect to all variables. Pearson Correlation Coefficients was used to study the correlation between Kisspeptin, BMI and other studied variables. Genotype and allele frequencies were calculated manually https:// ihg.gnf.de/cgi-bin/hw/hwa1.pl. Significance of the difference in the result of POCS cases and controls was obtained using Fisher's Exact test (two-tailed) and odds ratios, 95\% confidence intervals, $\chi^{2}$ and $p$ value were obtained. All statistical analyses were performed by using SPSS for Windows (version 9.3).

\section{Results}

Basic anthropometrics and hormonal features of the study group are summarized in Table 1 . Women with PCOS had significantly higher weight, BMI and LH level compared to the control group $(p<.0001)$. No significant differences in FSH and kisspeptin level between groups were observed. Kisspeptin level were higher in PCOS women compared to control group, but not 
Table 1 Comparisons of clinical parameters amongst PCOS and control group

\begin{tabular}{|c|c|c|c|}
\hline Variable & $\begin{array}{l}\text { PCOS Group } \\
(n=28) \\
\text { Mean } \pm \text { SD) })\end{array}$ & $\begin{array}{l}\text { Control Group } \\
(n=30) \\
\text { Mean } \pm S D))\end{array}$ & $P$-value \\
\hline Age (years) & $29.4 \pm 3.93$ & $26.7 \pm 3.6$ & 0.008 \\
\hline Weight (Kg) & $72.63 \pm 12.8$ & $59.87 \pm 10.8$ & 0.0001 \\
\hline Height (cm) & $155.9 \pm 6.9$ & $161.5 \pm 4.1$ & 0.001 \\
\hline BMI $\left(\mathrm{Kg} \backslash \mathrm{m}^{2}\right)$ & $46.04 \pm 7.3$ & $36.6 \pm 8.17$ & 0.0001 \\
\hline FSH (IU\) & $6.81 \pm 5.4$ & $5.7 \pm 1.95$ & 0.325 \\
\hline LH (IU\I) & $15.12 \pm 3.7$ & $8.73 \pm 1.16$ & 0.0001 \\
\hline $\begin{array}{l}\text { Kisspeptin } \\
\text { (pg\mL) }\end{array}$ & $0.43 \pm .15$ & $0.39 \pm .07$ & 0.178 \\
\hline
\end{tabular}

significantly. Kisspeptin level were found to be positively correlated with LH level in the PCOS patients $(r=0.604$; $p=0,005$, control: $r=0.409 ; p=0.007)$. Correlations between kisspeptin level, hormonal and anthropometric measurement of women studied are summarized in Table 2. Direct sequencing of KISS1 gene revealed several SNPs. The SNP rs4889 (C/G) was detected more frequently in PCOS group than in control, and this nonsynonymous SNP results in the substitution of P81R. Distribution of rs4889 C/G in KISS1 gene and the allele and genotype frequencies in PCOS and control groups are summarized in Table 3. Statistically significant differences were observed for the alleles $(p=0.0057)$, and genotype frequency between PCOS and controls. Allele $\mathrm{C}$ showed higher frequency in PCOS group (37.5\%) than control group (15\%). The individuals with the different genotypes were separated and the levels of the anthropometric and hormonal parameters and kisspeptin were separately analyzed for each genotype. Table 4 presents the results of the study variables in the different rs4889 genotypes (CC, CG and GG) in Saudi women with PCOS and Control groups. Statistically significant difference were observed in the wild type GG in women with PCOS in weight $(\mathrm{Kg})(75.83 \pm 11.42$ vs. 57.59 $\pm 10.07, p<.0001)$, and

Table 2 Correlations between kisspeptin level, hormonal and anthropometric measurement of PCOS patients and control group

\begin{tabular}{|c|c|c|c|c|c|c|}
\hline \multirow{2}{*}{$\begin{array}{l}\text { Correlation } \\
\text { between } \\
\text { kisspeptin } \\
\text { and }\end{array}$} & \multicolumn{3}{|c|}{$\begin{array}{l}\text { PCOS Group } \\
(n=28)\end{array}$} & \multicolumn{3}{|c|}{$\begin{array}{l}\text { Controls Group } \\
(n=30)\end{array}$} \\
\hline & $r$ & $p$ & Sig & $r$ & P & Sig \\
\hline Age (years) & 0.182 & 0.355 & NS & 0.083 & 0.663 & NS \\
\hline Weight (Kg) & 0.111 & 0.575 & NS & 0.152 & 0.422 & NS \\
\hline Height (cm) & -0.118 & 0.549 & NS & -0.177 & 0.351 & NS \\
\hline BMI $\left(\mathrm{Kg} / \mathrm{m}^{2}\right)$ & 0.165 & 0.401 & NS & 0.109 & 0.567 & NS \\
\hline FSH (IU/I) & 0.049 & 0.804 & NS & 0.225 & 0.231 & NS \\
\hline LH (IU/I) & 0.604 & 0.005 & S & 0.409 & 0.007 & $S$ \\
\hline
\end{tabular}

NS non-significant $=p>0.05, S$ significant $=p \leq 0.05, r$ correlation coefficient
Table 3 Frequencies of allele and genotypes of rs4889 C/G in KISS1 gene in PCOS and control groups

\begin{tabular}{lllllll}
\hline Variation & $\begin{array}{l}\text { Control } \\
(N=30)\end{array}$ & $\begin{array}{l}\text { Case } \\
(28)\end{array}$ & OR & Cl & $\underline{X}^{2}$ & $P$-value \\
\hline CC & $1(3.3)$ & $4(14.3)$ & 8.0 & $0.79-80.4$ & 3.96 & 0.046 \\
CG & $7(23.3)$ & $13(46.4)$ & 3.714 & $1.15-11.96$ & 5.04 & 0.024 \\
GG & $22(73.3)$ & $11(39.4)$ & 0.125 & $0.012-1.26$ & 3.96 & 046 \\
CG + GG & $29(0.48)$ & $24(0.43)$ & 0.207 & $0.02-1.98$ & 2.21 & 0.137 \\
C & $9(0.15)$ & $21(0.375)$ & 3.4 & $1.4-8.3$ & 7.65 & 0.006 \\
G & $51(0.85)$ & $35(0.625)$ & 0.294 & $0.12-0.72$ & 7.65 & 0.006 \\
\hline \multicolumn{7}{l}{ OR odds ratio, Cl confidence intervals, $\chi^{2}$ chi square, $P$ significance }
\end{tabular}

in BMI (wt/ht $\left.{ }^{2}\right)(48.32 \pm 6.73$ vs $35.01 \pm 8.04, p<.0001)$. Statistically significant difference were observed in the heterozygous CG in LH level $(13.73 \pm 3.35$ vs. $8.741 \pm$ $1.28, P<.0001)$. The effect of the different genotypes of rs4889 on the level of of kisspeptin was studied and as shown in the Table 4. The kisspeptin level did not differ significantly in individuals with the CC, CG and GG genotypes in PCOS group and GG and CG in control group. Only one control had CC genotype and was not included in the calculations.

\section{Discussion}

The present study investigated plasma kisspeptin levels in Saudi women with and without PCOS and studied the nature of correlation between kisspeptin, anthropometric parameters and PCOS-related reproductive hormones. It also evaluated the sequence of exons in the KISS-1 gene and compared the frequency of rs4889 C/G, a non-synonymous SNP, in PCOS and controls. Our investigation showed that the level of kisspentin was slightly higher in females with PCOS, though the results compared to the control group were not significantly different. Three previous studies [18-20] reported higher kisspeptin levels in women with PCOS. Another study [21] reported lower levels in women with PCOS as compared to controls. Yerlikaya et al., [22] study and our study did not support these findings. This may be the result of the obesity and insulin resistance that may have negative impact on kisspeptin levels.

The Kiss-1 system has emerged in the recent years as a fundamental player in the control of the reproductive axis, with essential roles in differentiation and pubertal activation of the reproductive system as well as key functions in the regulation of ovulation and fertility [18]. Kisspeptin has been recently associated with increased $\mathrm{GnRH}$ and regulates the secretion of $\mathrm{LH}$ during the promotion of ovulation $[23,24]$. PCOS is a condition associated with disordered hypothalamic-pituitary-gonadal axis, higher LH levels, compared to ovulatory women without the syndrome $[25,26]$. The present study 
Table 4 Level of anthropometric parameters and hormones in different genotypes of rs4889 C/G in KISS1 gene in Saudi women with PCOS and Control groups

\begin{tabular}{|c|c|c|c|c|c|c|c|c|}
\hline \multirow[t]{2}{*}{ Variable } & \multicolumn{3}{|c|}{$\begin{array}{l}\text { PCOS Group } \\
(n=28) \\
(\text { Mean } \pm \text { SD) }\end{array}$} & \multicolumn{2}{|c|}{$\begin{array}{l}\text { Control Group } \\
(n=30) \\
(\text { Mean } \pm \text { SD })\end{array}$} & \multicolumn{3}{|l|}{$P$-value } \\
\hline & $\begin{array}{l}\mathrm{GG} \\
n=11\end{array}$ & $\begin{array}{l}C G \\
n=13\end{array}$ & $\begin{array}{l}C C \\
n=4\end{array}$ & $\begin{array}{l}\mathrm{GG} \\
n=22\end{array}$ & $\begin{array}{l}C G \\
n=7\end{array}$ & $\overline{\mathrm{GG}}$ & $C G$ & $\mathrm{CC}$ \\
\hline Weight (Kg) & $75.8 \pm 11$ & $74.1 \pm 13$ & $58.8 \pm 4.1$ & $57.5 \pm 10$ & $68.4 \pm 9.6$ & $0.0001^{* *}$ & 0.362 & 0.157 \\
\hline Height (cm) & 156. \pm 6.8 & $156 \pm 7.5$ & $152 \pm 5.91$ & $162 \pm 3.9$ & $158.8 \pm 3.5$ & $0.007^{*}$ & 0.660 & 0.468 \\
\hline BMI $\left(\mathrm{Kg} / \mathrm{m}^{2}\right)$ & $48.3 \pm 6.7$ & $47.2 \pm 7.5$ & $38 \pm 1.76$ & $35 \pm 8$ & $42.6 \pm 6.43$ & $0.0001^{* *}$ & 0.219 & 0.157 \\
\hline FSH (IU/I) & $6.52 \pm 5.6$ & $7.64 \pm 5.8$ & $4.9 \pm 4.02$ & $5.8 \pm 2$ & $5.5 \pm 1.4$ & 0.879 & 0.475 & 1.00 \\
\hline LH (IU/I) & $13.7 \pm 3.3$ & $16.2 \pm 3.8$ & $15.3 \pm 3.7$ & $8.7 \pm 1.2$ & $8.6 \pm 0.89$ & $0.0001^{* *}$ & $0.0001^{* *}$ & 0.147 \\
\hline kisspeptin (pg\mL) & $0.38 \pm 0.2$ & $0.43 \pm 0.1$ & $0.35 \pm 0.18$ & $0.37 \pm .06$ & $0.45 \pm 0.06$ & 0.349 & 0.968 & 1.00 \\
\hline
\end{tabular}

There was only 1 sample with a CC genotype in the control group, and was not used in the comparison

${ }^{*} p$-value $<0.05 ;{ }^{* *} p$-value $<0.001$

evaluated the possible role of kisspeptin in the pathophysiology of PCOS and showed the correlation between levels of kisspeptin and LH. Several groups have now reported that kisspeptin administered either centrally or peripherally, stimulate gonadotropin secretion. Similar observations were reported in the rat [27, 28], sheep [29], monkey $[30,31]$ and more recently, the human male [32]. Our study showed that LH levels were higher in PCOS women compared to controls, and plasma kisspeptin levels were positively correlated with LH levels. It was consistent with the idea that kisspeptin may stimulate LH secretion, although the way of direct pituitary effects of kisspeptin in the control of gonadotropin secretion remains controversial [33, 34]. In another study conducted by Panidis et al., [21], it was found that LH levels were significantly higher in PCOS groups compared to controls. This finding was in line with the results of the present study. However, no significant correlation between plasma kisspeptin and $\mathrm{LH}$ levels was observed in their study, and they also found that obese and overweight women with PCOS had significantly lower kisspeptin levels compared to normal weight women with the syndrome. These conclusions are contradictory to our study, possibly due to differences in the BMI in these studies as well as methodological differences. Additionally, small sample size and the heterogeneity of the study groups are the limitations of these previous studies. Plasma kisspeptin levels were measured by Chen et al. [19] in 42 women with PCOS (23 adult, 19 adolescents) and 20 adolescent controls to investigate the possible correlations between kisspeptin and PCOS related reproductive and metabolic disturbances. Their results suggested that plasma kisspeptin levels were increased in lean adolescent and adult women with PCOS compared with lean adolescent control group. Our study did not support these findings. Moreover, LH levels of both adult and adolescent PCOS women were higher than that of adolescent controls and kisspeptin showed a positive correlation with $\mathrm{LH}$ similar to the findings of our study. Some researchers have demonstrated that kisspeptin may play a key role in the activation of the gonadotropic axis at puberty $[35,36]$. So elevated kisspeptin levels of adolescent PCOS may play a role as a marker to recognize PCOS in adolescents more clearly and sometimes at an earlier stage. In the study of Chen and coworkers [19], the number of the controls was relatively small and no adult controls were involved. Therefore, it needs further research to draw any conclusions. Plasma kisspeptin levels were measured by Jeon et al. [20] in 54 women with PCOS and 36 controls. Their results suggested that plasma kisspeptin levels were significantly higher in the PCOS group than in controls; however, they did not find correlations between kisspeptin and any of the hormones. The data of Yilmaz et al., [18] claimed that women with PCOS exhibited higher kisspeptin levels than controls. Furthermore, kisspeptin concentrations were found to be in a positive correlation with $\mathrm{LH}$ levels.

In this study, polymorphism in SNP rs4889 C/G was detected more frequently in PCOS group than in control $(p$-value $=0.0057)$. Allele $\mathrm{C}$ showed higher frequeny in PCOS group (37.5\%) than control group (15\%). When the results in different genotypes were compared, the weight and BMI were higher, while the LH level was lower in the GG genotype, in the PCOS patients and the results were significantly different. Kisspeptin was higher in the GG genotype but the results were not significantly different. When compared with the control group, the weight, height and BMI were significantly higher in PCOS carrying GG genotype, compared to the controls with the same genotype. LH was higher in all genotypes in the PCOS, compared to the results in the control group.

rs4889 polymorphism introduced a substitution of proline for arginine at the 81 position. This is a substitution that was observed in kisspeptin-54, but not in the other three forms of kisspeptin (kisspeptin-14, - 13, 
and -10). This SNP is found in the coding region and results in the substitution of an imino acid Pro by a basic amino acid Arg. Change in the DNA sequence as a result of this polymorphisms could alter the structure, function and binding capacity of kisspeptin to its receptor GPR54.. Previous studies in Korean and Chinese populations found no relationship between this SNP and CPP [37, 38]. From the results of this study, it appears that rs4889 influences the mechanism by which kisspeptin activates secretion of LH but not FSH. Further studies are necessary to investigate the possible mechanisms involved in kisspeptin function and mode of action.

\section{Conclusion}

In conclusion, this study has shown significant relationship between the rs $4889 \mathrm{C} / \mathrm{G}$ polymorphisms in KISS1 gene and PCOS in Saudi females, where the mutant $\mathrm{G}$ allele is highly protective $(\mathrm{OR}=0.294 ; 95 \%$ $\left.\mathrm{CI}=0.12-0.72, \quad \mathrm{X}^{2}=7.65 ; p=0.006\right)$. The LH levels were higher in the women with PCOS, compared to the controls, and plasma kisspeptin levels positively correlated with $\mathrm{LH}$ levels. Within the genotypes of rs4889 the LH levels were significantly lower in the GG compared to the CG and CC genotypes in the PCOS females. The mechanism of kisspeptin for regulating gonadotropin secretion remains unknown. Discrepant findings among the results of the published studies may be attributed to the design and sample size and the demographic and genetic characteristics of the different populations.

The major limitation of our study was the small number of the studied sample. Further studies are warranted, to get a clearer picture of the mechanisms that bring about the interaction between kiss-1 gene and different hormonal parameters.

\section{Acknowledgements}

The authors extend their appreciation to the National Plan for Science, Technology and Innovation (MAARIFAH), King Abdul-Aziz City for Science and Technology, Kingdom of Saudi Arabia, grant Number No 08-MED 604-2. We thank all the subjects for their cooperation and participation in the study. We would also like to thank all the participants (researchers, technicians and nurses) for their notable contribution.

\section{Funding}

This Work was funded by the National Plan for Science, Technology and Innovation (MAARIFAH), King Abdul-Aziz City for Science and Technology, Kingdom of Saudi Arabia, grant Number No 08-MED 604-2.

\section{Availability of data and materials}

Due to ethical concerns, the data of the present study cannot be openly available.

\section{Declarations}

The study protocol was approved by the local ethical committee Makkah, Kingdom of Saudi Arabia. All participants attending the out-patient Gynecology Clinic were enrolled in the study, after taking their informed consent.

\section{Authors' contributions}

FSA and MHD designed the study, obtained all the needed chemicals, kits and other requirements, conducted all analysis and contributed to the writing of the manuscript. MHD ${ }^{2}$ enrolled the patients, obtained informed consent, and collected all the clinical data. AME conducted statistical analysis and contributed to the writing of the paper. ASW performed the genetics data analysis and contributed to the writing of the paper. All authors read and approved the final manuscript.

\section{Ethics approval and consent to participate}

Ethical approval was obtained from the Institutional Review Board (IRB), Umm Al-Qura University, Makkah, Kingdom of Saudi Arabia (IRB No. 235) and each female was required to sign an informed consent form. All participants gave a written informed consent prior to inclusion in the study.

\section{Competing interests}

The authors declare that they have no competing interests.

\section{Publisher's Note}

Springer Nature remains neutral with regard to jurisdictional claims in published maps and institutional affiliations.

\section{Author details}

'Department of Zoology, Center for Scientific and Medical Female Colleges, King Saud University, P.O. Box 22455, Riyadh 11495, Saudi Arabia.

${ }^{2}$ Department of Obstetrics \& Gynecology, Umm-Al-Qura University, P.O. Box 424, Makkah 21955, Saudi Arabia. ${ }^{3}$ Department of Biostatistics, Epidemiology \&Scientific Computing, King Faisal Specialist Hospital and Research Center, P.O. Box 3354, Riyadh 11211, Saudi Arabia. ${ }^{4}$ Central Laboratory, Center for Scientific and Medical Female Colleges, King Saud University, P.O. Box 22455, Riyadh 11495, Saudi Arabia.

Received: 8 January 2018 Accepted: 22 May 2018

Published online: 30 May 2018

\section{References}

1. Hori A, Honda S, Asada M, Ohtaki T, Oda K, Watanabe T, et al. Metastin suppresses the motility and growth of $\mathrm{CHO}$ cells transfected with its receptor. Biochem Biophys Res Commun. 2001;286:958-63.

2. Lee JH, Miele ME, Hicks DJ, Phillips KK, Trent JM, Weissman BE, et al. KiSS-1, a novel human malignant melanoma metastasis-suppressor gene. J Natl Cancer Inst. 1996;88:1731-7.

3. Ohtaki T, Shintani Y, Honda S, Matsumoto H, Hori A, Kanehashi K, et al. Metastasis suppressor gene KiSS-1 encodes peptide ligand of a G-proteincoupled receptor. Nature. 2001;411:613-7.

4. Muir Al, Chamberlain L, Elshourbagy NA, et al. AXOR12, a novel human G protein-coupled receptor, activated by the peptide KiSS-1. J Biol Chem. 2013;276:28969-75.

5. deRoux N, Genin E, Carel JC, Matsuda F, Chaussain JL, Milgrom E. Hypogonadotropic hypogonadism due to loss of function of the KiSS1-derived peptide receptor GPR54. Proc Natl Acad Sci U S A. 2003;100:10972-6.

6. Funes S, Hedrick JA, Vassileva G, et al. The KiSS-1 receptor GPR54 is essential for the development of the murine reproductive system. Biochem Biophys Res Commun. 2003;312:1357-63.

7. Babiker A, Al Shaikh A. The role of kisspeptin signalling in control of reproduction in genetically similar species. Sudan J Paediatr. 2016;16(1):9-16.

8. Castellano JM, Gaytan M, Roa J, et al. Expression of KiSS-1 in ratovary: putativelocal regulator of ovulation? Endocrinology. 2006;147:4852-62.

9. Matsui H, Takatsu Y, Kumano S, Matsumoto H, Ohtaki T. Peripheral administration of metastin induces marked gonadotropin release and ovulation in the rat. Biochem Biophys Res Commun. 2004;320:383-8.

10. Navarro VM, Castellano JM, Fernández-Fernández R, et al. Characterization of the potent luteinizing hormone-releasing activity of KiSS-1 peptide, the natural ligand of GPR54. Endocrinology. 2005;146:156-63.

11. Wojciechowski P, Lipowska A, Rys P, et al. Impact of FTO genotypes on BMI and weight in polycystic ovary syndrome: a systematic review and metaanalysis. Diabetologia. 2012;55:2636-45.

12. Panidis D, Koliakos G, Kourtis A, Farmakiotis D, Mouslech T, Rousso D. Serum resistin levels in women with polycystic ovary syndrome. Fertil Steril. 2004;81:361-6. 
13. Panidis D, Farmakiotis D, Rousso D, Katsikis I, Kourtis A, Diamanti-Kandarakis E. Serum luteinizing hormone levels are markedly increased and significantly correlated with _4-androstenedione levels in lean women with polycystic ovary syndrome. Fertil Steril. 2005;84:538-40.

14. Goodarzi MO, Korenman SG. The importance of insulin resistance in polycystic ovary syndrome. Fertil Steril. 2003:80:255-8.

15. Franks S. Polycystic ovary syndrome. N Engl J Med. 1995;333:853-61.

16. Ehrmann DA, Barnes RB, Rosenfield RL, Cavaghan MK, Imperial J. Prevalence of impaired glucose tolerance and diabetes in women with polycystic ovary syndrome. Diabetes Care. 1999;22:141-6.

17. Adam J, Franks S, Polson DW, Mason HD, Abdulwahid N, Tucker M. Multifollicular ovaries: clinical and endocrine features and response to pulstile gonadotrophin.releasing hormone. Lancet. 1985;2:1375-8.

18. Yilmaz SA, Se cilmis Kerimoglu O, Pekin A, Incesu F, Dogan NU, Celik C, Unlu A. Metastin levels in relation with hormonal and metabolic profile in patients with polycystic ovary syndrome. Eur J Obstet Gynecol Reprod Biol. 2014;180:56-60

19. Chen X, Mo Y, Li L, Chen Y, Li Y, Yang D. Increased plasma metastin levels in adolescent women with polycystic ovary syndrome. Eur J Obstet Gynecol Reprod Biol. 2010;149(1):72-6.

20. Jeon YE, Lee KE, Jung JA, et al. Kisspeptin, leptin, and retinol-binding protein 4 in women with polycystic ovary syndrome. Gynecol Obstet Investig. 2013;75:268-74.

21. Panidis D, Rousso D, Koliakos G, et al. Plasma metastin levels are negatively correlated with insulin resistance and free androgens in women with polycystic ovary syndrome. Fertil Steril. 2006;85:1778-83.

22. Yerlikaya E, Akin F, Turgut S, Yaylali G, Topsakal S, Ayada C, Hatipoglu C. Plasma kisspeptin levels in polycystic ovary syndrome. Endocr Abstr. 2013:32:618

23. Gottsch ML, Cunningham MJ, Smith JT, Popa SM, Acohido BV, Crowley WF, et al. A role for kisspeptins in the regulation of gonadotropin secretion in the mouse. Endocrinology. 2004;145:4073-7.

24. Navarro VM, Castellano JM, Fernandez-Fernandez R, Tovar S, Roa J, Mayen A, et al. Characterization of the potent LH releasing activity of KiSS-1 peptide, the natural ligand of GPR54. Endocrinology. 2005;146:156-63.

25. Diamanti-Kandarakis E, Dunaif A. New perspectives in polycystic ovary syndrome. Trends Endocrinol Metab. 1996;7:267-71.

26. Allahbadia GN, Merchant R. Polycystic ovarian syndrome and impact on health. Mid East Fert Soc J. 2011;16:19-37.

27. Matsui T, Doi R, Mori T, et al. Metastin and its variant forms suppress migration of pancreatic cancer cells. Biochem Biophys Res Commun. 2004:315:85-92.

28. Navarro VM, Castellano JM, Fernandez-Fernandez R, et al. Effects of KiSS-1 peptide, the natural ligand of GPR54, on follicle-stimulating hormone secretion in the rat. Endocrinology. 2005;146:1689-97.

29. Messager S, Chatzidaki EE, Ma D, et al. Metastin directly stimulates gonadotropin- releasing hormone secretion via $\mathrm{G}$ proteincoupled receptor 54. Proc Natl Acad Sci U S A. 2005;102:1761-6.

30. Shahab M, Mastronardi C, Seminara SB, Crowley WF, Ojeda SR, Plant TM. Increased hypothalamic GPR54 signaling: a potential mechanism for initiation of puberty in primates. Proc Natl Acad Sci U S A. 2005;102:2129-34.

31. Plant TM, Ramaswamy S, DiPietro MJ. Repetitive administration of hypothalamic $\mathrm{G}$ protein-coupled receptor 54 with intravenous pulses of metastin in the juvenile monkey (Macaca mulatta) elicits a sustained train of gonadotropin-releasing hormone discharges. Endocrinology. 2006;147:1007-13.

32. Dhillo WS, Chaudhri OB, Patterson M, et al. Metastin-54 stimulates the hypothalamic-pituitary gonadal axis in humanmales. J Clin Endocrinol Metab. 2005:90:6609-15.

33. Irwig MS, Fraley GS, Smith JT, et al. Metastin activation of gonadotropin releasing hormone neurons and regulation of KiSS-1mRNA in the male rat. Neuroendocrinology. 2004;80:264-72.

34. Castellano JM, Navarro VM, Fernandez-Fernandez R, et al. Changes in hypothalamic KiSS-1 system and restoration of pubertal activation of the reproductive axis by metastin in undernutrition. Endocrinology. 2005;146:3917-25

35. Castellano JM, Navorro VM, Fernandez-Fernandez R, Roa J, Vigo E, Pinedo R, et al. Expression ofhypothalamic Kiss-1 system and rescue of defective gonadotropic responses by Kisspeptin in Streptozotocin-induced diabetic male rats. Diabetes. 2006:55:2602-10.
36. Balen $\mathrm{AH}$, Dunger D. Pubertal maturation of the internal genitalia Ultrasound Obstet Gynaecol. 1995;6:164-5. [Commentary]

37. Ko JM, Lee HS, Hwang JS. KISS1 gene analysis in Korean girls with central precocious puberty: a polymorphism, p.P110T, suggested to exert a protective effect. Endocr J. 2010;57:701-9.

38. Luan X, Zhou Y, Wang W, Yu H, Li P, Gan X, Wei D, Xiao J. Association study of the polymorphisms in the KISS1 gene with central precocious puberty in Chinese girls. Eur J Endocrinol. 2007;157:113-8.

\section{Ready to submit your research? Choose BMC and benefit from:}

- fast, convenient online submission

- thorough peer review by experienced researchers in your field

- rapid publication on acceptance

- support for research data, including large and complex data types

- gold Open Access which fosters wider collaboration and increased citations

- maximum visibility for your research: over $100 \mathrm{M}$ website views per year

At BMC, research is always in progress.

Learn more biomedcentral.com/submissions 